\title{
Efficiency of Urban Bus Companies in India: A Stochastic Frontier Analysis
}

\author{
Sanjay K. Singh \\ Indian Institute of Management, Lucknow, India \\ Email: sanjay@iiml.ac.in
}

How to cite this paper: Singh, S.K. (2017) Efficiency of Urban Bus Companies in India: A Stochastic Frontier Analysis. Theoretical Economics Letters, 7, 1925-1939. https://doi.org/10.4236/tel.2017.77130

Received: September 22, 2017 Accepted: November 19, 2017 Published: November 22, 2017

Copyright (C) 2017 by author and Scientific Research Publishing Inc. This work is licensed under the Creative Commons Attribution International License (CC BY 4.0).

http://creativecommons.org/licenses/by/4.0/

\begin{abstract}
The main aim of this paper is to measure the technical efficiency of publicly owned urban bus companies (UBCs) in India for the period 2000-01 to 2012-13. To examine the efficiency as well as determinants of the same, we estimated a stochastic production frontier based on a translog production function using the maximum likelihood methods. The empirical results reveal that profit and fleet utilization have a significant influence on technical efficiency of UBCs. We find that substantial inefficiencies, averaging between 12 to 41 percent, exist; in general, small and large size UBCs are more efficient than their medium size counterparts. Therefore, there exists no linear relationship between technical efficiency and firm size. We also examined the temporal relationship of the cross-sectional rankings of individual UBCs' technical efficiency estimates. To address this issue, we calculated Kendall's index of rank concordance and coefficient of variation of technical efficiency for sample period. It is found that, by and large, there has been stability in ranks across UBCs in regard to their technical efficiency.
\end{abstract}

\section{Keywords}

Urban Bus Companies, Efficiency, Stochastic Frontier Analysis, India

\section{Introduction}

Public transport system in urban India heavily relies on its bus transport system. Bus transport services are now available in most of the metropolitan cities, thanks to the Government of India's Jawaharlal Nehru National Urban Renewal Mission (JNNURM) [1]. Services are mostly run by publicly owned Urban Bus Companies (UBCs), which are usually called either State Transport Undertakings (STUs) or Municipal Transport Undertakings (MTUs). The STUs operate in the hands of the respective state governments whereas MTUs are controlled by the respective 
municipal governments.

UBCs in India operate with around 24,000 buses and employ close to 156,000 people. During the year 2012-13, latest year for which data are available, the total bus-kilometers operated by them were more than 1.6 billion and the volume of operations had crossed the mark of 80 billion passenger-kilometers. However, from the very beginning, UBCs in India faced huge financial losses from their operation. UBCs' total revenue during the year 2012-13 was just Rs. 66,025 million in comparison to total cost of Rs. 109,345 million. Due to this, they faced a net loss of more than Rs. 43 billion during the year 2012-13. On an average, every bus-km operated by these companies resulted in a loss of more than Rs. 25 during the same year.

Nevertheless, since UBCs in India offer their services with a social aim, financial losses faced by them are not bad per se. For government owned public transport companies, efficiency is more important than profitability. Efficiency has long been a critical consideration in both policy and operational decisions of public transport operators, and public transport efficiency has recently become even more vital [2]. However, bus transport efficiency is often more difficult to evaluate since it is challenging to determine the accurate amount of resources required to produce various service outputs [3].

There are several approaches to measure transport operators' efficiency; parametric and non-parametric frontiers are the two main approaches to measure efficiency (for comparison, see, [4] [5] [6] [7] [8]). Parametric frontier approach postulates that efficient units operate on the production or cost frontier, while inefficient ones operate either below the frontier (in case of the production frontier) or above the frontier (in the case of the cost frontier). Thus, a one-sided error term, in addition to the traditional symmetric noise term, is incorporated in the model to capture inefficiencies [9]. Non-parametric approach, the data envelopment analysis (DEA) method, was developed by Farrell [10]. This method does not require any specification of the functional form of the production or cost technology. Also, DEA makes no adjustment for random noise, and can be sensitive to outlier observations [11]. Another drawback of DEA is that statistical inference and hypothesis tests cannot be conducted for the estimated efficiency scores [12].

The main of aim of this paper is to examine the efficiency of UBCs in India in a manner that allows the efficiency to vary both over time as well as across firms. The analysis is conducted using the stochastic frontier analysis (SFA) of the production function model specified by Battese and Coelli [13] for panel data. The study also identifies the determinants of (in) efficiency. To examine the efficiency of UBCs and determinants of the same, we estimate a stochastic production frontier based on a translog production function using maximum likelihood methods. Annual data for a sample of eight UBCs from 2000-01 to 2012-13 are used for the purpose of estimation. Sample is based on availability of consistent data. Sample UBCs have quite similar organizational structure. Also, they operate under more or less similar operational environment. The statistical program Frontier Ver- 
sion 4.1 is used for the estimation purpose. At the end, we also examined whether the efficiency ranks of the UBCs differ significantly over the years. To address this issue, we calculated Kendall's index of rank concordance and coefficient of variation of technical efficiency for sample period. Basically, we would like to determine if the UBCs that were inefficient earlier are still inefficient or whether there has been any convergence.

The remainder of this paper is organized as follows: Section 2 discusses the approach used to estimate the technical efficiency and choice of functional form. Section 3 describes the sample UBCs and the data. Section 4 presents the results. Section 5 concludes the study.

\section{Technical Efficiency in Urban Bus Companies: Approach and Functional Form}

In line with the work of Battese and Coelli [13] on estimation of technical efficiency by using a stochastic frontier approach, we specify stochastic frontier production function for panel data as:

$$
Y_{i t}=\exp \left(X_{i t} \beta+V_{i t}-U_{i t}\right)
$$

where, $Y_{i t}$ is output of $i^{\text {th }}$ firm $(i=1,2, \cdots, N)$ in the $t^{\text {th }}$ period $(t=1,2, \cdots, T)$; $X_{i t}$ is a $(1 \times K)$ vector of input quantities of the $i^{\text {th }}$ firm in the $t^{\text {th }}$ period; $\beta$ is a $(K \times 1)$ vector of unknown parameters to be estimated; $V_{i t}$ is a random variable which is assumed to be independent and identically distributed and have $N\left(0, \sigma_{V}^{2}\right)$ distribution and independent of $U_{i t}$; the $U_{i t}$ is non-negative random variable, associated with technical inefficiency of production, which is assumed to be independently distributed as truncations at zero of the $N\left(\mu, \sigma_{U}^{2}\right)$ distribution, where $\mu=Z_{i t} \delta$; and $Z_{i t}$ is a $(1 \times P)$ vector of explanatory variables associated with technical inefficiency of the $I^{\text {th }}$ firm in the $t^{\text {th }}$ period and $\delta$ is a $(P \times 1)$ vector of unknown parameters to be estimated.

A number of empirical studies (e.g., [14] [15]) have estimated stochastic frontiers and predicted firm level inefficiencies using models similar to Equation (1) [16]. They then regress the predicted inefficiencies on firm specific variables (such as managerial experience, ownership characteristics, capacity utilization, etc.) in an attempt to identify some of the reasons for differences in predicted inefficiencies among firms in an industry. However, the two-stage estimation procedure renders this method less efficient than one in which the frontier and the determinants of efficiency are estimated in a single stage [13]. Therefore, we estimate the stochastic frontier as well as the determinants of inefficiency in a single stage. We estimate the following along with the stochastic frontier:

$$
U_{i t}=Z_{i t} \delta+W_{i t}
$$

where, $W_{i t}$ is an unobservable random variable assumed to be independently distributed, obtained by truncation of the normal distribution with mean zero and variance, $\sigma^{2}$, such that the $U_{i t}$ is non-negative. The condition that $U_{i t}$ is non-negative ensures that all observations lie on or below the production frontier. 
Given the specification of the model, the hypothesis that the technical efficiency effects are non-random is expressed by $H_{0}: \gamma=0$, where $\gamma=\sigma_{U}^{2} /\left(\sigma_{U}^{2}+\sigma_{V}^{2}\right)$. Battese and Corra [17] showed that the parameter, $\gamma=\sigma_{U}^{2} /\left(\sigma_{U}^{2}+\sigma_{V}^{2}\right)$, has a value between zero and one; $\gamma=0$ indicates that the deviations from the frontier are entirely due to noise, while $\gamma=1$ would indicate that all deviations from the frontier are due to technical inefficiency. The hypothesis that the technical efficiency effects are not influenced by the level of explanatory variables in Equation (2) is examined by testing the statistical significance of $\delta$. After obtaining the estimates of $U_{i t}$, the technical efficiency (TE) of $i^{\text {th }}$ firm during $t^{\text {th }}$ period is obtained as:

$$
T E_{i t}=\exp \left(-U_{i t}\right)=\exp \left(-Z_{i t} \delta-W_{i t}\right)
$$

Since stochastic production function estimation requires a specific functional form of the production function, we specified (1) by the translog production function:

$$
\ln Y=\beta_{0}+\sum_{k=1}^{K} \beta_{k} \ln X_{k}+\frac{1}{2} \sum_{k=1}^{K} \sum_{l=1}^{K} \beta_{k l} \ln X_{k} \ln X_{l}+V-U
$$

where all the variables have their previous meaning. It can be noted that when $\beta_{k l}=0$, the translog production function reduces to a Cobb-Douglas one.

De Borger et al. [18] and Jarboui et al. [8] provide an overview of public transport efficiency studies and present the various inputs and outputs used in frontier studies. Jarboui et al. [8] shows that financial variables are more robust since they reduce the problem reflected by the use of demand or supply-oriented variables. The use of labor, fuel, and buses as inputs poses a problem of substitution between inputs. Non-substitutable inputs may lead to inefficient firms reported as efficient ones. Also, if we have large number of inputs and outputs, firms' efficiency scores are likely to be higher [19].

Therefore, a single variable as a measure of output and two variables as inputs is used for this study. The total number of employees and the total operating expenses are used as inputs and traffic revenue is used to measure the output. Total operating expenses include expenses on fuel (diesel and CNG if any), lubricants, springs, auto spare parts, tyres and tubes, batteries, general items, reconditioned items, etc. These expenses are related to the operation of buses; therefore, total operating expenses could be viewed as a proxy for physical inputs. Many studies (e.g., [12] [19] [20] [21]) affirm that outputs related to demand particularly the revenue or sales of the firm should be used as the measure of output to assess firms' efficiency. Consequently, in this study, traffic revenue is used to measure the output of UBCs. Therefore, Equation (4) can be modified as:

$$
\begin{aligned}
\ln Y_{i t}= & \beta_{0}+\beta_{1} \ln X_{1 i t}+\beta_{2} \ln X_{2 i t}+\frac{1}{2} \beta_{11}\left(\ln X_{1 i t}\right)^{2}+\frac{1}{2} \beta_{22}\left(\ln X_{2 i t}\right)^{2} \\
& +\beta_{12} \ln X_{1 i t} \ln X_{2 i t}+V_{i t}-U_{i t}
\end{aligned}
$$

where $Y$ is traffic revenue (Rs. in million), $X_{1}$ is total number of employees, and $X_{2}$ is total operating expenses (Rs. in million). 
Another objective of this study is to identify determinants of technical efficiency. Various studies have examined the inefficiency determinants, but they have tendency to focus on the variables such as market organization, regulatory system, network characteristics, etc. which are outside the firm's control [19]. In most cases, bus operators are unable to act on these determinants to improve their efficiency. Nevertheless, there are other robust determinates of inefficiency such as investment, profit, and firm size which are under firm's control. Mohapatra and Dutta [22] and Ahern and Anandarajah [23] affirm that investment is an important determinant of public transport operators' efficiency since investment is a necessity for improving quality, reliability, system security, punctuality, etc. Unfortunately, consistent investment data for UBCs in India are not available. However, fleet utilization, defined as the ratio (in percentage terms) of buses on road to the buses held by the UBCs, data are available which can be used as a proxy for investment. Since profit is an important source of internal financial investments in productive activity of the firm, profitable operators can improve the quality of service and consequently, efficiency as well. Therefore, we can consider firm's profit as an important determinant of inefficiency. Size of the firm also plays an important role in determining the efficiency. Lun and Quaddus [24] have shown that firm size has a positive effect on efficiency. Halkos and Tzeremes [25] argue that firm size has an indirect impact on firms' productivity because it determines the impact of internal productivity factors. Consequently, firm size can also be considered as one of the determinants of inefficiency. Therefore, Equation (2) can be modified as:

$$
U_{i t}=\delta_{0}+\delta_{1} Z_{1 i t}+\delta_{2} Z_{2 i t}+\delta_{3} Z_{3 i t}+W_{i t}
$$

where $Z_{1}$ is fleet utilization (in \% age), $Z_{2}$ is profit (Rs. in million), and $Z_{3}$ is firm size (Bus-Km in million).

The estimation is carried out using the maximum likelihood methods from the statistical program Frontier Version 4.1 where the stochastic frontier i.e., Equation (5), as well as the determinants of inefficiency i.e., Equation (6), are estimated in a single stage. We sought simpler models nested in base model on the basis of the likelihood ratio (LR) test. The LR test statistic is written as:

$$
\lambda=2\left[l\left(h_{u}\right)-l\left(h_{r}\right)\right]
$$

where $l\left(h_{u}\right)$ represents the value of the log of the likelihood function with unrestricted values of parameters and $l\left(h_{r}\right)$ represents the log of the likelihood function with maximum likelihood estimation of the parameter vector $h$ with $r$ restrictions. The statistic $\lambda$ is distributed as a $\chi^{2}$ with $r$ degrees of freedom under the null hypothesis that the restrictions hold.

\section{Sample UBCs and the Data}

Annual data for a sample of eight UBCs from 2000-01 to 2012-13 are used for the purpose of estimation. Sample is based on availability of consistent data. Sample UBCs include Bangalore Metropolitan Transport Corporation (BMTC), Cal- 
cutta State Transport Corporation (CSTC), Delhi Transport Corporation (DTC), Ahmedabad Municipal Transport Service (AMTS), Brihanmumbai Electricity Supply and Transport Undertaking (BEST), Kolhapur Municipal Transport Undertaking (KMTU), Thane Municipal Transport Undertaking (TMTU), and Metropolitan Transport Corporation Limited (Chennai) (MTCL). Table 1 presents some recent descriptive statistics of these UBCs. The main source of data is Performance Statistics of STUs, 2000-01 to 2012-13 published by the Central Institute of Road Transport (CIRT), Pune, India.

Sample UBCs are publicly owned, operate throughout their respective jurisdiction (often throughout the city), mainly provide intra-urban bus transport services, and do business in the field of passenger transportation only, but differ in size and the level of output produced. The size of the UBCs, as measured by bus-kilometers (BKm) in 2012-13, ranges from 11 million BKm for KMTU to 464 million BKm for BMTC. Fleet strength of UBCs varies drastically, from 139 buses for KMTU to 6330 buses for BMTC. Number of workers employed by UBCs also varies from 1058 for KMTU to 36,796 for BEST. In almost all respect, KMTU is the smallest UBC whereas BMTC is the largest one.

\section{Results}

\subsection{Results on the Production Frontier}

Table 2 presents the results of the maximum likelihood estimation. The study specifies four alternative translog stochastic production frontier models. The log likelihood ratio test shows that Model 1 is the best model (see, Table 3); virtually all the coefficients of Model 1 are statistically significant. The hypothesis test results confirm that the translog production model is more appropriate in comparison to the Cobb-Douglas production model. Table 3 results also show that the technical inefficiency effects are stochastic and are associated with the explanatory variables, namely fleet utilization, profit, and firm size.

In Model 1, the estimated value of $\gamma$ is greater than zero and statistically significant which implies the presence of random component of the technical

Table 1. Descriptive statistics of the sample UBCs during 2012-13.

\begin{tabular}{cccccccc}
\hline UBCs & $\begin{array}{c}\text { Pass.-Km } \\
\text { (million) }\end{array}$ & $\begin{array}{c}\text { Bus-Km } \\
\text { (million) }\end{array}$ & $\begin{array}{c}\text { Pass. carried } \\
\text { (million) }\end{array}$ & $\begin{array}{c}\text { No. of } \\
\text { employees }\end{array}$ & $\begin{array}{c}\text { No. of } \\
\text { buses held }\end{array}$ & $\begin{array}{c}\text { Traffic } \\
\text { revenue/bus-km (Rs.) }\end{array}$ & Profit/bus-km (Rs.) \\
\hline BMTC & 21,056 & 464 & 1769 & 34,273 & 6330 & 33 & -3 \\
DTC & 18,797 & 354 & 1075 & 34,376 & 5603 & 32 & -82 \\
MTCL & 18,796 & 344 & 1754 & 23,519 & 3585 & 32 & -3 \\
BEST & 11,446 & 265 & 1410 & 36,796 & 4259 & 49 & -24 \\
AMTS & 1902 & 54 & 240 & 5428 & 1120 & 25 & -35 \\
CSTC & 1218 & 26 & 108 & 5485 & 779 & 34 & -57 \\
TMTU & 670 & 15 & 88 & 2313 & 313 & 44 & -25 \\
KMTU & 390 & 11 & 27 & 1058 & 139 & 31 & -1 \\
\hline
\end{tabular}


Table 2. Estimates of production frontier and determinants of inefficiency (with t-statistic in parentheses).

\begin{tabular}{|c|c|c|c|c|c|}
\hline \multirow{2}{*}{ Variables } & \multirow{2}{*}{ Parameters } & \multicolumn{4}{|c|}{ Estimated MLE coefficients } \\
\hline & & Model 1 & Model 2 & Model 3 & Model 4 \\
\hline Constant & $\beta_{0}$ & $\begin{array}{l}2.011 \\
(1.97)\end{array}$ & $\begin{array}{l}7.024 \\
(7.14)\end{array}$ & $\begin{array}{l}3.875 \\
(3.32)\end{array}$ & $\begin{array}{l}5.902 \\
(3.09)\end{array}$ \\
\hline $\ln$ (total number of employees) & $\beta_{1}$ & $\begin{array}{c}-1.711 \\
(3.53)\end{array}$ & $\begin{array}{c}-1.817 \\
(2.87)\end{array}$ & $\begin{array}{c}-2.252 \\
(4.29)\end{array}$ & $\begin{array}{c}-1.205 \\
(1.30)\end{array}$ \\
\hline $\ln$ (total operating expenses) & $\beta_{2}$ & $\begin{array}{l}2.936 \\
(5.79)\end{array}$ & $\begin{array}{l}1.494 \\
(1.74)\end{array}$ & $\begin{array}{l}3.058 \\
(5.49)\end{array}$ & $\begin{array}{l}1.583 \\
(2.11)\end{array}$ \\
\hline $1 / 2 \star[\ln (\text { total number of employees })]^{2}$ & $\beta_{11}$ & $\begin{array}{l}0.566 \\
(3.83)\end{array}$ & $\begin{array}{l}0.289 \\
(0.64)\end{array}$ & $\begin{array}{l}0.652 \\
(4.13)\end{array}$ & $\begin{array}{l}0.242 \\
(0.83)\end{array}$ \\
\hline $1 / 2 *^{*}[\ln (\text { total operating expenses })]^{2}$ & $\beta_{22}$ & $\begin{array}{l}0.323 \\
(2.51)\end{array}$ & $\begin{array}{c}0.006 \\
(0.007)\end{array}$ & $\begin{array}{l}0.336 \\
(2.35)\end{array}$ & $\begin{array}{l}0.050 \\
(0.19)\end{array}$ \\
\hline $\begin{array}{c}{[\ln (\text { total number of employees })]^{*}} \\
[\ln \text { (total operating expenses })]\end{array}$ & $\beta_{12}$ & $\begin{array}{l}-0.476 \\
(3.38)\end{array}$ & $\begin{array}{c}-0.081 \\
(0.15)\end{array}$ & $\begin{array}{c}-0.502 \\
(3.28)\end{array}$ & $\begin{array}{r}-0.139 \\
(0.53)\end{array}$ \\
\hline Constant & $\delta_{0}$ & $\begin{array}{l}2.583 \\
(5.75)\end{array}$ & $\begin{array}{l}0.064 \\
(0.07)\end{array}$ & $\begin{array}{c}-2.881 \\
(0.51)\end{array}$ & $\begin{array}{l}1.262 \\
(8.27)\end{array}$ \\
\hline Fleet utilization & $\delta_{1}$ & $\begin{array}{c}-0.0336 \\
(4.34)\end{array}$ & $\begin{array}{c}-0.0079 \\
(0.44)\end{array}$ & & \\
\hline Profit & $\delta_{2}$ & $\begin{array}{c}-0.0000234 \\
(2.27)\end{array}$ & & $\begin{array}{c}-0.0000797 \\
\quad(0.67)\end{array}$ & \\
\hline Firm size & $\delta_{3}$ & $\begin{array}{l}0.0001 \\
(0.14)\end{array}$ & & & $\begin{array}{c}-0.0045 \\
(6.72)\end{array}$ \\
\hline Sigma-squared & $\sigma^{2}=\sigma_{U}^{2}+\sigma_{v}^{2}$ & $\begin{array}{l}0.093 \\
(3.27)\end{array}$ & $\begin{array}{l}0.254 \\
(0.92)\end{array}$ & $\begin{array}{l}0.939 \\
(0.61)\end{array}$ & $\begin{array}{l}0.060 \\
(4.18)\end{array}$ \\
\hline Gamma & $\gamma=\frac{\sigma_{U}^{2}}{\sigma_{U}^{2}+\sigma_{v}^{2}}$ & $\begin{array}{c}0.951 \\
(33.62)\end{array}$ & $\begin{array}{l}0.932 \\
(1.05)\end{array}$ & $\begin{array}{c}0.996 \\
(143.99)\end{array}$ & $\begin{array}{l}0.885 \\
(5.58)\end{array}$ \\
\hline Log likelihood function & & 37.687 & 1.753 & 6.595 & 19.272 \\
\hline
\end{tabular}

Table 3. Likelihood ratio test for functional form (value of log likelihood function for base model (i.e., Model 1): 37.687).

\begin{tabular}{ccccc}
\hline Restrictions imposed on coefficients & Value of $\lambda$ & Critical & $\chi_{0.95}^{2}$-value & Decision on $H_{0}$ \\
\hline$\delta_{2}=\delta_{3}=0$ & 71.87 & 5.99 & Rejected \\
$\delta_{1}=\delta_{3}=0$ & 62.18 & 5.99 & Rejected \\
$\delta_{1}=\delta_{2}=0$ & 36.83 & 5.99 & Rejected \\
$\gamma=\delta_{0}=\delta_{1}=\delta_{2}=\delta_{3}=0$ & 87.14 & 11.07 & Rejected \\
$\beta_{11}=\beta_{22}=\beta_{12}=0$ & 17.85 & 7.81 & Rejected \\
\hline
\end{tabular}

inefficiency effects. Therefore, the term $U_{i t}$ cannot be excluded from the regression and parameter estimation by the method of ordinary least squares is inappropriate. In the MLE estimation, $\gamma$ is positive and statistically significant, implying that public bus transport industry specific technical efficiency is important in explaining the total variability of yield produced. However, it may be noted 
that 95 percent of the variation in production is due to technical inefficiency and only 5 percent is due to the stochastic random error.

The signs of the coefficients of Model 1 reveal that total operating expenses is a key factor for production and therefore, its increase will yield positive returns. The signs of the inefficiency determinants estimated coefficients show that fleet utilization and profit negatively affect the transport operators' technical inefficiency. That is, fleet utilization and firms' profit assist the transport operators to be more efficient. Since fleet utilization largely depends on average age of buses and their maintenance, it is directly related to the investment made by the firms. Consequently, investment in terms of new buses and materials affect the technical efficiency of transport operators. Therefore, the greater the capital invested, the more the company is technically efficient. The negative sign of $\delta_{2}$ reveals that technical efficiency can be affected by the availability of financial resources.

Most of the transport operators in our sample have faced financial losses during almost every year of the sample period; however, firms which face lesser losses are more efficient than those that have accumulated huge losses. For example, in 2012-13, losses faced by BMTC, MTCL, and KMTU was less than $10 \%$ of their traffic revenue while their average efficiency score was 0.937 whereas losses faced by DTC, AMTS, and CSTC was more than 100\% of their traffic revenue and their average efficiency score was only 0.647 . Model 1 result shows that technical efficiency does not vary with firm size; the hypothesis that $\delta_{3}$ is equal to zero could not be rejected even at ten percent level of significance. However, the estimated coefficient of firm size in Model 4 is negative and statistically significant. This indicates that larger bus transport operators are likely to be more technically efficient than their smaller counterparts since larger firms are able to invest more in new technology and assets than the smaller ones. Table 2 results reveal that the technical efficiency of bus transport operators can be explained by fleet utilization (which heavily depends on investment in new buses and maintenance of the old ones), firms' profit, and firm size. These variables, particularly fleet utilization and profit, are indicators of managerial efficiency; in other words, technical efficiency of bus transport operators is directly related to managerial efficiency. Therefore, public bus transport operators can improve their technical efficiency by improving their managerial efficiency.

\subsection{Results on the Technical Efficiency}

Table 4 reports summary statistics of the estimates of technical efficiency in UBCs. UBCs can be classified into three size categories on the basis of their size (measured in terms of bus-km during the mean of the sample period). The size-wise list of UBCs (with million bus-km in parentheses) is: 1) Large size UBCs: BMTC (333.5), DTC (205.4), MTCL (206.1), and BEST (236.8); 2) Medium size UBCs: AMTS (58.9) and CSTC (50.8); and 3) Small size UBCs: TMTU (15.9) and KMTU (11.8). We find that substantial inefficiencies, averaging between 12 to 41 percent, exist in UBCs. However, both the mean and median estimates of technical 
Table 4. Summary statistics of technical efficiency in UBCs: 2000-01 to 2012-13.

\begin{tabular}{ccccc}
\hline & Large size UBCs & Medium size UBCs & Small size UBCs & All the UBCs \\
\hline Mean & 0.829 & 0.589 & 0.881 & 0.782 \\
Median & 0.895 & 0.521 & 0.906 & 0.870 \\
Minimum & 0.542 & 0.352 & 0.661 & 0.352 \\
Maximum & 0.981 & 0.954 & 0.951 & 0.981 \\
$\begin{array}{c}\text { Coefficient } \\
\text { of variation }(\mathrm{CoV})\end{array}$ & 0.159 & 0.342 & 0.094 & 0.233 \\
$\mathrm{~N}$ & 52 & 26 & 26 & 104 \\
\hline
\end{tabular}

efficiency are lower for medium size UBCs than their other counterparts. This suggests that, on an average, small and large size UBCs deviate less from their respective production frontier than medium size UBCs. Moreover, coefficient of variation of technical efficiency is the lowest for small size UBCs and the highest for medium size ones. The relationship of technical efficiency and coefficient of variation of the same with firm size is quite similar; neither technical efficiency nor coefficient of variation of technical efficiency has positive or negative relationship with the firm size. Table 4 and Table 5 figures clearly show that there is no linear relationship between technical efficiency of UBCs and their size.

Table 5 reveals that CSTC, which provides bus transport services in Kolkata, was the least efficient firm in 2000-01 as well as in 2012-13, whereas BEST, which provides bus transport services in Mumbai, was the most efficient firm in 2012-13 and the second most efficient firm in 2000-01. Among the sample UBCs, BEST is the most consistent performer closely followed by BMTC which provides bus transport services in Bangalore. Average technical efficiency of BEST and BMTC is 92.5\% (with coefficient of variation of only 0.025 ) and $92.4 \%$ (with coefficient of variation of 0.040 ), respectively. The third most efficient firm, KMTU, with average technical efficiency of $88.4 \%$ is the smallest in size whereas fourth most efficient firm, TMTU, is the second smallest in size.

Table 5 also reports aggregate technical efficiency of sample UBCs. If we take it as a proxy for the industry, then there is evidence of improvement in technical efficiency in the industry, over the sample period. Result shows that the average technical efficiency of publicly owned urban bus transport industry in India is $82 \%$. Last but one row of the same table reveals that the BEST, BMTC, KMTU, and TMTU experienced more than industry average technical efficiency whereas CSTC, DTC, AMTS, and MTCL faced less than the industry average technical efficiency. This means that $50 \%$ UBCs performed better than industry whereas remaining 50\% performed worse than industry. Among the worst performers, average technical efficiency of DTC (65.7\%), which provides bus transport services in Delhi, and CSTC (41.3\%) is conspicuously lower than the industry average (82.0\%). 
Table 5. Technical efficiency of UBCs: 2000-01 to 2012-13.

\begin{tabular}{cccccccccc}
\hline & BMTC & DTC & MTCL & BEST & AMTS & CSTC & TMTU & KMTU & $\begin{array}{c}\text { Weighted } \\
\text { average }\end{array}$ \\
\hline 2000-01 & 0.869 & 0.669 & 0.699 & 0.894 & 0.700 & 0.352 & 0.912 & 0.661 & 0.743 \\
$2001-02$ & 0.942 & 0.975 & 0.716 & 0.909 & 0.677 & 0.392 & 0.936 & 0.812 & 0.863 \\
2002-03 & 0.963 & 0.608 & 0.821 & 0.932 & 0.593 & 0.408 & 0.894 & 0.899 & 0.805 \\
$2003-04$ & 0.981 & 0.584 & 0.813 & 0.914 & 0.587 & 0.419 & 0.879 & 0.944 & 0.799 \\
$2004-05$ & 0.967 & 0.600 & 0.767 & 0.896 & 0.575 & 0.401 & 0.883 & 0.941 & 0.791 \\
$2005-06$ & 0.958 & 0.646 & 0.725 & 0.907 & 0.763 & 0.385 & 0.845 & 0.949 & 0.799 \\
$2006-07$ & 0.927 & 0.570 & 0.734 & 0.902 & 0.804 & 0.426 & 0.854 & 0.907 & 0.790 \\
$2007-08$ & 0.907 & 0.546 & 0.799 & 0.942 & 0.871 & 0.430 & 0.895 & 0.929 & 0.813 \\
$2008-09$ & 0.867 & 0.542 & 0.844 & 0.926 & 0.909 & 0.466 & 0.904 & 0.951 & 0.815 \\
$2009-10$ & 0.892 & 0.624 & 0.905 & 0.954 & 0.954 & 0.460 & 0.923 & 0.936 & 0.857 \\
$2010-11$ & 0.895 & 0.741 & 0.863 & 0.954 & 0.885 & 0.417 & 0.878 & 0.940 & 0.856 \\
$2011-12$ & 0.932 & 0.758 & 0.900 & 0.934 & 0.768 & 0.400 & 0.916 & 0.670 & 0.866 \\
$2012-13$ & 0.915 & 0.679 & 0.945 & 0.961 & 0.850 & 0.412 & 0.698 & 0.951 & 0.863 \\
Mean & 0.924 & 0.657 & 0.810 & 0.925 & 0.764 & 0.413 & 0.878 & 0.884 & 0.820 \\
CoV & 0.040 & 0.178 & 0.098 & 0.025 & 0.169 & 0.073 & 0.068 & 0.117 & 0.046 \\
\hline
\end{tabular}

All the UBCs except TMTU experienced improvement in their efficiency over the sample period. Two UBCs, KMTU (44\%) and MTCL (35\%), achieved tremendous improvement in their technical efficiency in a span of twelve years from 2000-01 to 2012-13. AMTS (21\%) and CSTC (17\%) also experienced significant improvement; improvement in their technical efficiency was higher than that in the industry (16\%) during the sample period. Technical efficiency of BEST (7\%) and BMTC (5\%) improved only marginally. DTC (1\%), which is the second least efficient firm in the sample, experienced negligible change in its technical efficiency from 2000-01 to 2012-13. Only one firm, TMTU (-23\%), faced considerable decline in its technical efficiency. As far as fluctuation in technical efficiency is concerned, DTC was the most volatile and BEST was the least.

Finally, it is natural to ask whether the efficiency ranks of the UBCs differ significantly across the years. Specifically, we are interested in examining the temporal relationship of the cross-sectional rankings of individual UBCs' efficiency estimates. To address this issue, we calculate Kendall's index of rank concordance [26] along with coefficient of variation of technical efficiency for sample period. Basically, we would like to determine if the UBCs that were inefficient earlier are still inefficient or whether there has been any convergence. The results are presented in Table 6. The first column of Table 6 reports coefficient of variation of technical efficiency from 2000-01 to 2012-13. Figure 1 clearly shows that although coefficient of variation of technical efficiency is having a downward sloping trend particularly from 2004-05 till 2010-11, it is having increasing 


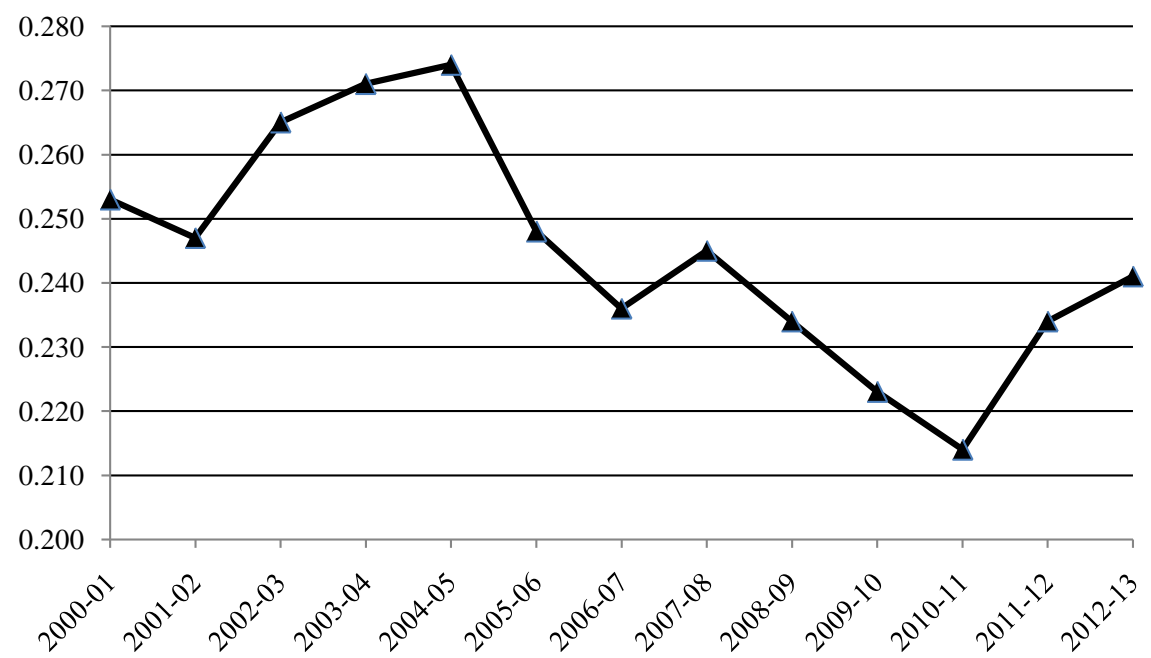

Figure 1. Coefficient of variation of technical efficiency: 2000-01 to 2012-13.

Table 6. Measures of convergence of technical efficiency in UBCs, 2000-01 to 2010-13.

\begin{tabular}{cccc}
\hline Year & $\begin{array}{c}\text { Coefficient of variation } \\
\text { of technical efficiency }\end{array}$ & $\begin{array}{c}\text { Kendall's index of } \\
\text { rank concordance }\end{array}$ & $\begin{array}{c}\chi^{2} \\
\text { for Kendall's index }\end{array}$ \\
\hline $2000-01$ & 0.253 & 1.0000 & 10.00 \\
$2001-02$ & 0.247 & $0.7143^{*}$ & 14.22 \\
$2002-03$ & 0.265 & $0.6773^{*}$ & 18.83 \\
$2003-04$ & 0.271 & 0.6726 & 24.67 \\
$2004-05$ & 0.274 & 0.7048 & 30.33 \\
$2005-06$ & 0.248 & 0.7222 & 36.38 \\
$2006-07$ & 0.236 & 0.7425 & 41.83 \\
$2007-08$ & 0.245 & 0.7470 & 45.04 \\
$2008-09$ & 0.234 & 0.7149 & 47.26 \\
$2009-10$ & 0.223 & 0.6752 & 53.15 \\
$2010-11$ & 0.214 & 0.6903 & 56.75 \\
$2011-12$ & 0.234 & 0.6756 & 61.11 \\
$2012-13$ & 0.241 & 0.6715 & \\
\hline
\end{tabular}

trend from 2001-02 to 2004-05 and 2010-11 till 2012-13. The second column of Table 6 reports Kendall's index of rank concordance, which is used to determine the association among the rankings obtained by various UBCs in different years (for a discussion on Kendall's index of rank concordance, see, [16] [26] [27]). Kendall's index of rank concordance is calculated as follows:

$$
K I_{t}=\frac{\operatorname{Variance}\left(\sum_{t=0}^{T} A R(T E)_{i t}\right)}{\operatorname{Variance}\left(\tau * A R(T E)_{i 0}\right)}
$$

where, $A R(T E)_{i t}$ is the actual rank of $i^{\text {th }}$ UBC in technical efficiency level in 
year t; $A R(T E)_{i 0}$ is the actual rank of $I^{\text {th }}$ UBC in technical efficiency level in the initial year 0 ; and $\tau$ is the number of years for which data are used in constructing the index.

The value of the Kendall's index of rank concordance ranges from zero to one. The denominator of the index is the maximum sum of ranks, which would be obtained if there is no change in rankings over time. The index is calculated for the first two sets of rankings (i.e., first two years), then for the first three sets of rankings and so on for all the sets of rankings (i.e., for all the years) [16]. The closer the index value is to zero the greater the extent of mobility of ranks over time. If convergence is present, the index will be less than one and close to zero. The statistic is distributed as chi-squared and we test the null hypothesis of no association between ranks of different years. The test statistic is

$$
\chi^{2}=\tau(N-1) K I
$$

where $\tau$ is the number of years of ranking, $N$ is the number of UBCs, and $K I$ is the calculated Kendall's index of rank concordance. There are $(N-1)$ degrees of freedom. Since critical value of chi-square at the $5 \%$ level of significance, $\chi_{0.05,7}^{2}$, is 14.07, the null hypothesis of no association between ranks of different years is rejected in all the cases except in two starred cases (see, Table 6). Hence, by and large, there has been stability in ranks across UBCs in regard to their technical efficiency.

\section{Concluding Remarks}

The efficiency of urban bus transport services has been exhaustively studied in developed countries (see, e.g., [28] [29] [30]). However, there are few such studies, particularly regarding technical efficiency of urban bus transport, for developing countries, and none, to the best of my knowledge, for India. This is the first study analyzing technical efficiency in urban bus transport in India using annual data of a sample of eight UBCs from 2000-01 to 2012-13.

To examine the technical efficiency of UBCs and determinants of the same, we estimated a stochastic production frontier based on a translog production function using maximum likelihood methods. The main findings of the study can be stated as follows. First, total operating expenses is a key factor for production and therefore, any increase in related inputs (fuel, lubricants, springs, auto spare parts, tyres and tubes, batteries, etc.) will yield positive returns. Second, fleet utilization and profit negatively affect the transport operators' inefficiency. That is, fleet utilization and firms' profit assist the operators to be more efficient. Since fleet utilization is directly related to the investment made by the firms, investment in terms of new buses and materials would make the operators more efficient. Similarly, since profitability and efficiency is positively related and most of the transport operators in our sample face financial losses, financial discipline and minimizing the losses would lead to improvement in their technical efficiency. Estimation result shows that technical efficiency does not vary significantly with firm size. Therefore, results reveal that the technical efficiency of UBCs can be ex- 
plained by their fleet utilization and profit. These two variables, in some ways, are indicators of UBCs' managerial efficiency. Therefore, UBCs can improve their technical efficiency by improving their managerial efficiency. This finding may be of interest to policy makers and company managers. They should try to have better understanding of inefficiencies and give more consideration to efficiency determinants.

Third, we find that substantial inefficiencies, averaging between 12 to 41 percent, exist in UBCs. In general, small and large size UBCs are more efficient than their medium size counterparts. There exists no linear relationship between technical efficiency of UBCs and their size. Among the sample UBCs, BEST was the most efficient firm followed by BMTC whereas CSTC was the least efficient. In fact, CSTC was the least efficient firm during every year from 2000-01 to 2012-13 whereas BEST was the most efficient during the last four years. Moreover, all the UBCs except one experienced improvement in their technical efficiency over the sample period.

Fourth, we examined the temporal relationship of the cross-sectional rankings of individual UBCs' technical efficiency estimates. To address this issue, we calculated Kendall's index of rank concordance along with coefficient of variation of technical efficiency for sample period. By and large, there has been stability in ranks across UBCs in regard to their technical efficiency. This shows that the UBCs that were relatively inefficient earlier are still relatively inefficient; consequently, there is no evidence of efficiency convergence among UBCs in India.

\section{Acknowledgements}

This paper is part of a seed money project on Performance Analysis of Public Transport in Indian Cities sponsored by the Indian Institute of Management, Lucknow, India. I thank the Director and Dean (Research) of the institute for providing me with an initiation grant for this study.

\section{References}

[1] Singh, S.K. and Raghav, S. (2013) Performance Analysis of Publicly Owned Urban Bus Companies in India. Indian Journal of Economics and Business, 12, 243-261.

[2] Barnum, D.T., Karlaftis, M.G. and Tandon, S. (2011) Improving the Efficiency of Metropolitan Area Transit by Joint Analysis of Its Multiple Providers. Transportation Research Part E, 47, 1160-1176. https://doi.org/10.1016/j.tre.2011.04.006

[3] Agarwal, S., Yadav, S.P. and Singh, S.P. (2010) DEA Based Estimation of the Technical Efficiency of State Transport Undertakings in India. Opsearch, 47, 216-230. https://doi.org/10.1007/s12597-011-0035-4

[4] Ferrier, G.D. and Lovell, C.K. (1990) Measuring Cost Efficiency in Banking: Econometric and Linear Programming Evidence. Journal of Econometrics, 46, 229-245. https://doi.org/10.1016/0304-4076(90)90057-Z

[5] Bjurek, H., Hjalmarsson, L. and Forsund, F.R. (1990) Deterministic Parametric and Nonparametric Estimation of Efficiency in Service Production: A Comparison. Journal of Econometrics, 46, 213-227. https://doi.org/10.1016/0304-4076(90)90056-Y 
[6] Lovell, C.K. (1993) Production Frontiers and Productive Efficiency. In: Fried, H.O., Lovell, C.K. and Schmidt, S.S., Eds., The Measurement of Productive Efficiency-Techniques and Applications, Oxford University Press, Oxford, 3-67.

[7] Cullinane, K., Wang, T.F., Song, D.W. and Ji, P. (2006) The Technical Efficiency of Container Ports: Comparing Data Envelopment Analysis and Stochastic Frontier Analysis. Transportation Research Part A, 40, 354-374. https://doi.org/10.1016/j.tra.2005.07.003

[8] Jarboui, S., Forget, P. and Boujelbene, Y. (2012) Public Road Transport Efficiency: A Literature Review via the Classification Scheme. Public Transport, 4, 101-128. https://doi.org/10.1007/s12469-012-0055-3

[9] Singh, S.K. and Venkatesh, A. (2003) Comparing Efficiency across State Transport Undertakings: A Production Frontier Approach. Indian Journal of Transport Management, 27, 374-391.

[10] Farrell, M.J. (1957) The Measurement of Productive Efficiency. Journal of the Royal Statistical Society. Series A (General), 120, 253-290. https://doi.org/10.2307/2343100

[11] Olatubi, W.O. and Dismukes, D.E. (2000) A Data Envelopment Analysis of the Levels and Determinants of Coal-Fired Electric Power Generation Performance. Utilities Policy, 9, 47-59. https://doi.org/10.1016/S0957-1787(01)00004-2

[12] Boame, A.K. (2004) The Technical Efficiency of Canadian Urban Transit Systems. Transportation Research Part E, 40, 401-416. https://doi.org/10.1016/j.tre.2003.09.002

[13] Battese, G.E. and Coelli, T.J. (1995) A Model for Technical Inefficiency Effects in a Stochastic Frontier Production Function for Panel Data. Empirical Economics, 20, 325-332. https://doi.org/10.1007/BF01205442

[14] Jha, R. and Singh, S.P. (1994) Inter-Temporal and Cross-Section Variations in Technical Efficiency in the Indian Railways. International Journal of Transport Economics/ Rivista internazionale di economia dei trasporti, 21, 57-73.

[15] Jørgensen, F., Pedersen, P.A. and Volden, R. (1997) Estimating the Inefficiency in the Norwegian Bus Industry from Stochastic Cost Frontier Models. Transportation, 24, 421-433. https://doi.org/10.1023/A:1004975000392

[16] Jha, R. and Singh, S.K. (2001) Small Is Efficient: A Frontier Approach to Cost Inefficiencies in Indian State Road Transport Undertakings. International Journal of Transport Economics/ Rivista internazionale di economia dei trasporti, 28, 95-114.

[17] Battese, G.E. and Corra, G.S. (1977) Estimation of a Production Frontier Model: With Application to the Pastoral Zone of Eastern Australia. Australian Journal of Agricultural and Resource Economics, 21, 169-179. https://doi.org/10.1111/j.1467-8489.1977.tb00204.x

[18] De Borger, B., Kerstens, K. and Costa, A. (2002) Public Transit Performance: What Does One Learn from Frontier Studies? Transport Reviews, 22, 1-38. https://doi.org/10.1080/01441640010020313

[19] Jarboui, S., Pascal, F. and Younes, B. (2013) Public Road Transport Efficiency: A Stochastic Frontier Analysis. Journal of Transportation Systems Engineering and Information Technology, 13, 64-71. https://doi.org/10.1016/S1570-6672(13)60123-3

[20] Saxena, P. and Saxena, R.R. (2010) Measuring Efficiencies in Indian Public Road Transit: A Data Envelopment Analysis Approach. Opsearch, 47, 195-204. https://doi.org/10.1007/s12597-011-0034-5

[21] Kumar, S. (2011) State Road Transport Undertakings in India: Technical Efficiency and Its Determinants. Benchmarking: An International Journal, 18, 616-643. https://doi.org/10.1108/14635771111166794 
[22] Mohapatra, P.K.J. and Dutta, R.K. (1990) An Intermodal Investment Decision Model in the Transport Sector. Omega, 18, 203-212. https://doi.org/10.1016/0305-0483(90)90067-J

[23] Ahern, A. and Anandarajah, G. (2007) Railway Projects Prioritisation for Investment: Application of Goal Programming. Transport Policy, 14, 70-80.

https://doi.org/10.1016/j.tranpol.2006.10.003

[24] Lun, Y.V. and Quaddus, M.A. (2011) Firm Size and Performance: A Study on the Use of Electronic Commerce by Container Transport Operators in Hong Kong. Expert Systems with Applications, 38, 7227-7234. https://doi.org/10.1016/j.eswa.2010.12.029

[25] Halkos, G.E. and Tzeremes, N.G. (2007) Productivity Efficiency and Firm Size: An Empirical Analysis of Foreign Owned Companies. International Business Review, 16, 713-731. https://doi.org/10.1016/j.ibusrev.2007.06.002

[26] Boyle, G.E. and McCarthy, T.G. (1997) A Simple Measure of $\beta$-Convergence. $\mathrm{OX}^{-}$ ford Bulletin of Economics and Statistics, 59, 257-264. https://doi.org/10.1111/1468-0084.00063

[27] Jha, R., Mohanty, M., Chatterjee, S. and Chitkara, P. (1999) Tax Efficiency in Selected Indian States. Empirical Economics, 24, 641-654. https://doi.org/10.1007/s001810050077

[28] Hensher, D.A. (1987) Productive Efficiency and Ownership of Urban Bus Services. Transportation, 14, 209-225. https://doi.org/10.1007/BF00837530

[29] De Rus, G. and Nombela, G. (1997) Privatisation of Urban Bus Services in Spain. Journal of Transport Economics and Policy, 31, 115-129.

[30] Karlaftis, M.G. (2004) A DEA Approach for Evaluating the Efficiency and Effectiveness of Urban Transit Systems. European Journal of Operational Research, 152, 354-364. https://doi.org/10.1016/S0377-2217(03)00029-8 